\title{
Erratum to: Attention Allocation in ASD: a Review and Meta-analysis of Eye-Tracking Studies
}

\section{Meia Chita-Tegmark ${ }^{1}$}

Published online: 2 September 2016

(C) Springer Science+Business Media New York 2016

\section{Erratum to: Rev J Autism Dev Disord}

\section{DOI:10.1007/s40489-016-0077-x}

Standard errors from the article by Shic et al. (2008) were incorrectly reported as standard deviations in Figures 4-6 and Fig. 9. The correct standard deviations and Cohen's d values are shown in the following table:

Table 1 Corrected standard deviations and Cohen's $d$ values for Shic et al., 2008

\begin{tabular}{cllr}
\hline & SD ASD & SD TD & $d$ \\
\hline Eyes/Fig. 4 & & & \\
2-year-olds & 1.67 & 1.94 & -0.53 \\
4-year-olds & 1.25 & 1.14 & 0.92 \\
Mouth/Fig. 5 & & & \\
2-year-olds & 0.52 & 1.18 & 0.58 \\
4-year-olds & 0.4 & 1.09 & 1.28 \\
Face/Fig. 6 & & & \\
2-year-olds & 2.08 & 2.4 & -0.35 \\
4-year-olds & 1.93 & 0.79 & 2.11 \\
Screen/Fig. 9 & & & -0.35 \\
2-year-olds & 2.08 & 2.4 & 2.11 \\
4-year-olds & 1.93 & 0.79 & \\
\hline
\end{tabular}

The online version of the original article can be found at doi:10.1007/s40489016-0077-x.

Meia Chita-Tegmark

meia@bu.edu

1 Department of Psychological and Brain Sciences, Boston University, 64 Cummington Street, Boston, MA 02215, USA
With these corrections, the mean effect sizes for each AOI change slightly as shown in the table below:

Table 2 Overall effect sizes for each AOI including corrected values for Shic et al., 2008

\begin{tabular}{lllll}
\hline & \multicolumn{3}{l}{ Overall effect size } & \\
\cline { 2 - 5 } & Mean & SE & $95 \%$ CI & \\
\hline Eyes & 0.38 & 0.08 & 0.21 & 0.55 \\
Mouth & 0.24 & 0.07 & 0.1 & 0.39 \\
Face & 0.45 & 0.11 & 0.25 & 0.66 \\
Screen & 0.64 & 0.15 & 0.35 & 0.93 \\
\hline
\end{tabular}

None of these changes are significant, leaving the conclusions unchanged. 